\title{
Waterspout cloud top detection using MSG SEVIRI infrared brightness temperature over the northern Ionian Sea, Greece
}

\author{
K. Papachristopoulou ${ }^{1,2}$, I. T. Matsangouras ${ }^{2,3}$, and P. T. Nastos ${ }^{2}$ \\ ${ }^{1}$ Department of Environmental Physics and Meteorology, Faculty of Physics, University of Athens, \\ Athens, Greece \\ ${ }^{2}$ Laboratory of Climatology and Atmospheric Environment, Faculty of Geology and Geoenvironment, \\ University of Athens, Athens, Greece \\ ${ }^{3}$ Hellenic National Meteorological Service, Athens, Greece
}

Correspondence to: K. Papachristopoulou (kpapachr@phys.uoa.gr)

Received: 15 January 2015 - Accepted: 23 March 2015 - Published: 13 April 2015

\begin{abstract}
Waterspouts pose a significant threat for coastal areas, maritime activities and structures and thus their study is essential. They are frequently occurring in the Mediterranean Sea and particularly in the northern coasts. A vulnerable area of waterspout formation is the Ionian Sea according to recent research and especially the water body around Corfu Island, Greece. The Laboratory of Climatology and Atmospheric Environment of the University of Athens has assembled a detailed database of waterspout events, providing additional information such as location and time of these events; valuable information for the methodology followed.

In this study, the waterspout data base concerns events from 20 March 2007 to 31 December 2013. Thus, a total of 74 events were recorded and catalogued on 47 days, as there were days with multiple waterspout events. The aim of this study is to investigate the temporal evolution of brightness temperature on tops of waterspout parent clouds that triggered the formation of single or multiple waterspout events, based on the aforementioned database. The cloud top temperature was assessed by using channel at $10.8 \mu \mathrm{m}$ MSG SEVIRI Level 1.5 Image Data product. The minimum brightness temperature of the cloud top around the waterspout location for four different examined radiuses was estimated during $60 \mathrm{~min}$ prior to and after waterspout formation. Results are illustrated in terms of seasonal analysis. During autumn season a decrease of brightness temperature (colder values) was detected at waterspout parent cloud close to waterspout formation.
\end{abstract}

\section{Introduction}

The characteristics of waterspouts have been described in detail by Golden (1968, 1971, 1973, 1974a, b, 1977, 2003), Leverson et al. (1977), Simpson et al. (1991), Golden and Sabones (1991), Golden and Bluestein (1993), Wakimoto and Lew (1993), and Rennó and Bluestein (2001). Waterspouts usually form under convective clouds (Golden, 1974a). Regions of local horizontal shear lines separating the updrafts from the downdrafts are favored for waterspout genesis (Golden, 1974a; Hess and Spillane, 1990), although this condition is necessary it is not a sufficient condition for waterspout formation (Simpson et al., 1991).
Waterspouts are not rare phenomena in the Mediterranean basin. Several publications during the last years presented their occurrence (e.g. Giaiotti et al., 2007; Gayà, 2011; Nastos and Matsangouras, 2010; Sioutas, 2011; Groenemeijer and Kühne, 2014; Matsangouras et al., 2014a). Regarding waterspout activity in Greece, the Laboratory of Climatology and Atmospheric Environment (LACAE, http://lacae.geol. uoa.gr) at the University of Athens, developed an open-ended online tornado reporting system (http://tornado.geol.uoa.gr), contributing to the compilation of a climatology of these extreme weather events (Matsangouras et al., 2014a; Matsangouras and Nastos, 2014). In particular, Matsangouras et al. (2014a), based on 2000-2012 tornado and waterspout 


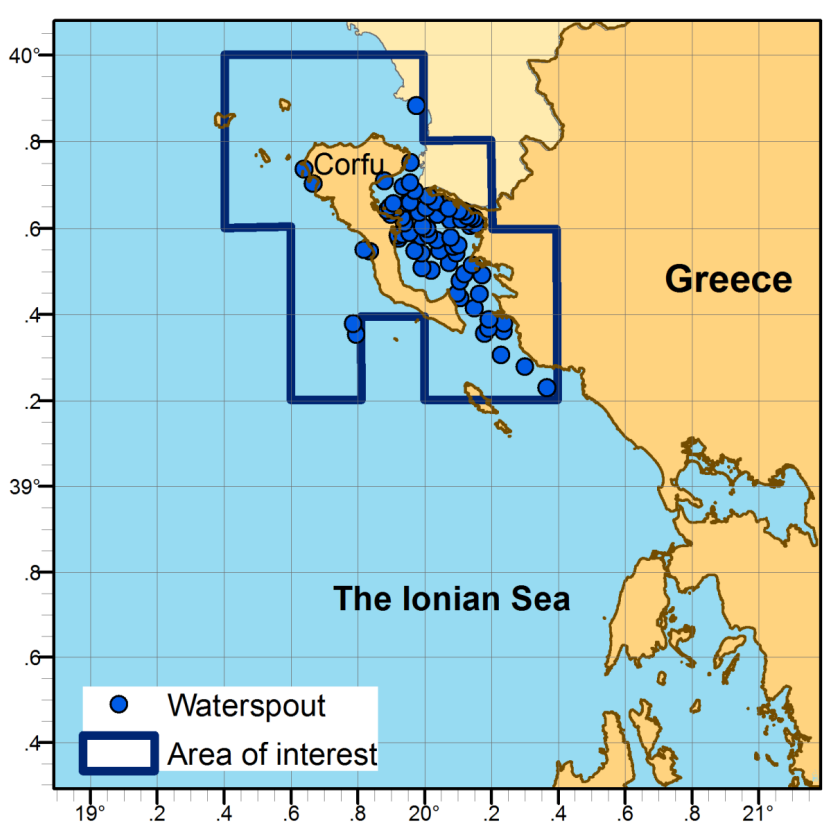

Figure 1. Spatial resolution of waterspout activity over the northern Ionian Sea and the area of study (blue line). Numerous waterspout events lie under the waterspout symbols, due to low resolution of the image.

database, showed that waterspouts have an annual mean of 27.64 event in Greece. Moreover, the most vulnerable areas for waterspout formation were around Crete island (in southern Greece), along the western parts of Greece, and over the northern Ionian Sea (Corfu, Fig. 1), with an annual mean of $11.23,9.69$, and 6.92, respectively. Keul et al. (2009), Sioutas and Keul (2007), and Matsangouras et al. (2014b) presented a spatial and temporal analysis of waterspout thermodynamic characteristics over the Ionian, and the Aegean Sea. Moreover, specific synoptic types favouring waterspout formation over the northern Ionian Sea were classified by Matsangouras et al. (2013), and an analysis of composite synoptic conditions relating to tornado and waterspout formation over western Greece was carried out by Nastos and Matsangouras $(2012,2014)$. Based on the abovementioned tornado database, a systematic scientific research project is in progress at LACAE, analyzing significant tornado case studies, numerical simulations, and investigating the contribution of Greek complex topography in tornadogenesis (e.g. Matsangouras and Nastos, 2010; Matsangouras et al., 2011, 2014c).

Remote sensing data (e.g. satellite or radar data) accelerated the enviromental research, by calculating significant atmospheric variables (e.g. temperature, wind, pressure) based on remote sensors for specific times and locations. Several publications (e.g. Barbosa et al., 2011; Barbosa and Ertürk, 2009; Bedka, 2011) illustrated the usage of Cloud Top Temperature (CTT) remote sensing variable, obtained from the infrared spectrum channel of $10.8 \mu \mathrm{m}$, as an essential tool in

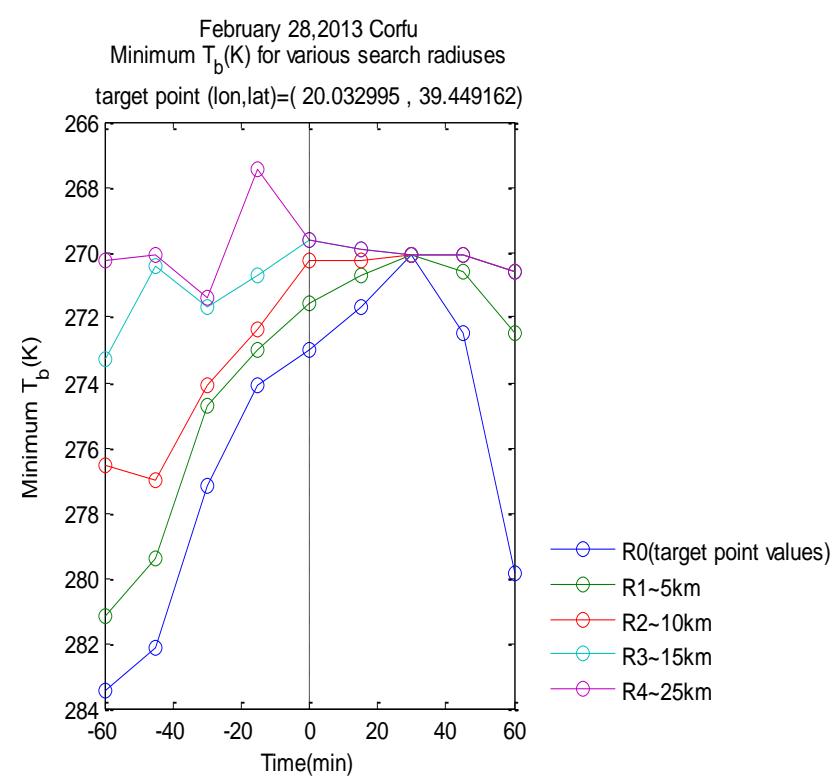

Figure 2. The temporal (60 min prior and after waterspout formation) distribution of BT during 28 February 2008 waterspout event for all examined radiuses.

cloud top detection applications and measuring the cloud top brightness temperature (BT). Papachristopoulou et al. (2014) presented a seasonal analysis of BT evolution during waterspout formation over the southern Aegean Sea.

In this study, a recent dataset of waterspout activity over the northern Ionian Sea is examined, with the implementation of weather satellite product, depicting the CTT of waterspout parent cloud. The objective of this paper is to investigate the temporal evolution of BT on tops of clouds (parent clouds) that triggered the formation of single or multiple waterspout event around Corfu island (in northern Ionian Sea, Greece).

\section{Data and methodology}

Regarding waterspouts data, they were derived from LACAE tornado database (Matsangouras et al, 2014a; Matsangouras and Nastos, 2014) and the study area concerns the sea around Corfu island (namely domain D1 in Matsangouras et al., 2014a) as illustrated in Fig. 1. The waterspout data base contains waterspout events from 20 March 2007 to $31 \mathrm{De}-$ cember 2013 (Fig. 1). A total of 74 events were recorded and catalogued on 47 days, as there were days with multiple waterspout events. Funnel clouds reports were categorized as waterspout events, taking into account waterspout 2 nd stage of life cycle (Golden, 1974b, 1977). The seasonal distribution of the 74 waterspout cases concerns 33, 19, 16, and 6 waterspout events during autumn, winter, spring, and summer, respectively. For every waterspout event detailed information was provided by the LACAE's database, including the time and the location of waterspout development. 


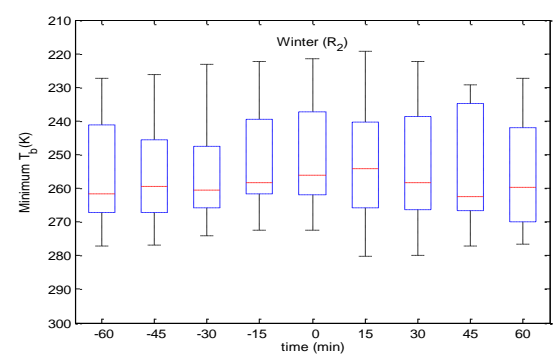

(a)

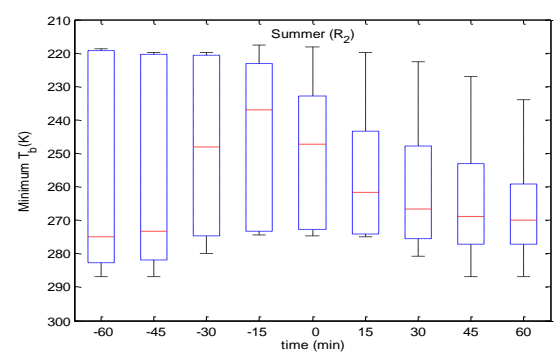

(c)

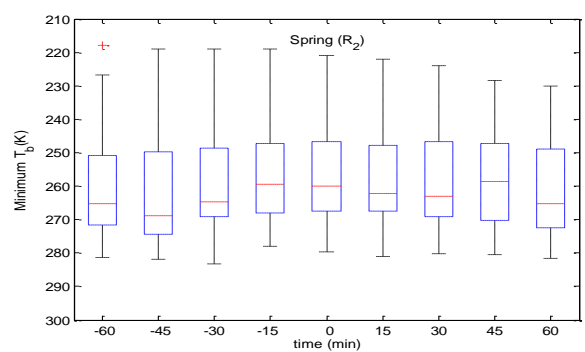

(b)

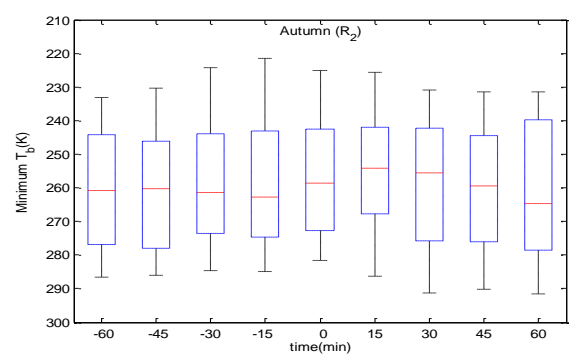

(d)

Figure 3. Box and whisker plots of minimum brightness temperature (BT) distribution (in K) at 60 min prior to and 60 min after waterspout formation, for $R_{2}$ search radius, during spring (a), summer (b), autumn (c), and spring (d) waterspout days over the northern Ionian Sea (2007-2013). On each plot, boxes show the upper (75th) and lower (25th) percentiles, the median (horizontal red line), while the whiskers extended to the most extreme data points, and outliers are plotted individually (red cross).

The CTT remote sensing data for every waterspout event were obtained from IR $10.8 \mu \mathrm{m}$ spectra channel (Chanel 9) of Meteosat Second Generation (MSG-2) and particularly the Spinning Enhanced Visible and InfraRed Imager (SEVIRI) instrument, operated by EUMETSAT. The MSG-2 SEVIRI radiometer (positioned at $0^{\circ}$ ), generates full disk images of the earth every $15 \mathrm{~min}$, thus, the CTT products were acquired for every waterspout event for a two hour period $(60 \mathrm{~min}$ prior and $60 \mathrm{~min}$ after waterspout formation time).

The spatial resolution of IR $10.8 \mu \mathrm{m}$ channel is $3 \times 3 \mathrm{~km}$, at sub-satellite point, and is reduced in our study area at $\sim 4 \mathrm{~km}$ to $\mathrm{E}-\mathrm{W}$ direction, and at $\sim 5 \mathrm{~km}$ to $\mathrm{N}-\mathrm{S}$ direction. For every $15 \mathrm{~min}$ scan BT values were calculated for four specific radiuses: (a) $5 \mathrm{~km}$ (hereafter, $R_{1}$ ), (b) $10 \mathrm{~km}$ (hereafter, $R_{2}$ ), (c) $15 \mathrm{~km}$ (hereafter $R_{3}$ ), and (d) $25 \mathrm{~km}$ (hereafter $\left.R_{4}\right)$. The selection of these radiuses is based on pixel spatial resolution, the parallax effect and the atmospheric scale of the phenomenon. In particular, waterspout parent clouds vary from 2 up to $10 \mathrm{~km}$ in diameter (Golden, 1974b). The parallax effect is a typical geometric effect related to satellite measurements. Indeed, the closer the satellite is to the globe, the larger is the parallax. The parallax effect at $6 \mathrm{~km}$ over the study area, based on EUMETSAT's tables, for the northern most and southern most waterspout location events was estimated at 4.6 and $4.5 \mathrm{~km}$, respectively. In addition, in this study we examined the CTT evolution of the parent cloud and not the CTT above the exact waterspout location.

Figure 2, illustrates results of the above-mentioned methodology for all search radiuses during the 28 February 2008 waterspout event over the northern Ionian Sea.

\section{Results and discussion}

In this section, we present the analysis of BT (in K) based on the seasonal distribution of waterspout days for every search radius. The analysis concerns a two hours temporal evolution of minimum BT from $T_{-X X}$ in minutes prior to waterspout formation and $T_{+X X}$ after waterspout formation.

For the sake of brevity, only $R_{2}$ search radius box-whiskers plots are shown in Fig. 3. The plot type was chosen to give an overview of data distribution and the same scale was kept for all plots for a better comparison. On each one of the boxes, the upper (75th) and lower (25th) percentiles along with the median as a horizontal line (red) were depicted, while the whiskers extended to the most extreme data points, and outliers were plotted individually (asterisc).

The $R_{1}$ radius results (not shown) during winter season, revealed a gradual decrease of median BT from 267 to $257 \mathrm{~K}$, starting from $T_{-60}$ to $T_{0}$ time of waterspout formation, revealing cloud increase in height. On the other hand, during 
autumn season the BT decrease is evident between $T_{-15}$ to $T_{+30}$ with the median fluctuating from 268 to $260 \mathrm{~K}$. However, the BT distribution did not show any significant change, as the median value of $264 \mathrm{~K}$, was the dominant value prior and after waterspout formation. In addition, during spring season from $T_{-45}$ to $T_{0}$ a slight decrease of BT was detected (from 270 to $264 \mathrm{~K}$ ). During summer, unlike other seasons, the BT distribution revealed a significant increase from 259 to $280 \mathrm{~K}$, starting from $T_{-15}$ to $T_{+60}$, suggesting a parent cloud top decrease in height.

The analysis for $R_{2}$ radius (Fig. 3), revealed that during winter season (Fig. 3a), the gradual decrease of BT (from 262 to $254 \mathrm{~K}$ ) is evident similar to $R_{1} \mathrm{BT}$ analysis, starting from $T_{-60}$ to $T_{+15}$ for this case. A slight decrease of median BT from 269 to $260 \mathrm{~K}$ and from 263 to $254 \mathrm{~K}$ is depicted in spring (Fig. 3b) and autumn (Fig. 3d) season distribution, starting from $T_{-45}$ to $T_{-15}$ and from $T_{-15}$ to $T_{+15}$ respectively. The summer season (Fig. 3c) BT distribution is characterized by an abrupt decrease of median BT (from 275 to $237 \mathrm{~K}$ ) in the time interval between $T_{-60}$ and $T_{-15}$ followed by a smooth increase.

Regarding the $R_{3}$ radius results (not shown), the BT values are lower in general, implying higher cloud tops, and revealed a smoother distribution. During winter season, the same pattern with previous radiuses is evident, BT decreases from $T_{-60}$ to $T_{+15}$ (from 256 to $241 \mathrm{~K}$ ). The slight decrease of median BT distribution during spring and autumn seasons, starting from $T_{-45}$ to $T_{-15}$ and from $T_{-15}$ to $T_{+15}$, respectively, is present and shifted to lower BT values (from 266 to $256 \mathrm{~K}$ and from 257 to $247 \mathrm{~K}$ for spring and autumn seasons, respectively). During summer season, the $R_{3}$ radius results revealed a smoother BT distribution. However, a significant decrease of BT from $T_{-45}$ to $T_{-30}$ (from 266 to $240 \mathrm{~K}$ ) and a significant increase of BT from $T_{-15}$ to $T_{+15}$ (from 237 to $262 \mathrm{~K}$ ) is evident.

Compared to $R_{3}$, the $R_{4}$ analysis (not shown) revealed a smoother distribution during all seasons, due to high search radius. According to $R_{4}$ analysis, the $\mathrm{BT}$ decrease during the winter season distribution, it is more evident around the waterspout formation time, with median BT values of 252 and $241 \mathrm{~K}$ for $T_{-15}$ and $T_{+15}$, respectively. The same pattern, with slighter decrease, is presented during spring and autumn season (from 259 to $251 \mathrm{~K}$ and from 249 to $247 \mathrm{~K}$, between $T_{-15}$ and $T_{+15}$, for spring and autumn season, respectively). Finally, the BT distribution for summer season is smoother, compared to other seasons, and the median BT values decrease between $T_{-60}$ and $T_{-15}$ (from 266 to $237 \mathrm{~K}$ ) and increase for the rest of the time interval (from 237 to $268 \mathrm{~K})$.

\section{Conclusions}

Our findings concern the seasonal distribution of the BT derived from CTT remote sensing product of MSG-2 SEVIRI instrument. The $R_{4}$ analysis revealed a smoother distribution of BT compared to the other radiuses, within all seasons, due to high search radius. A gradual decrease of median values of BT around waterspout formation time was detected at all search radiuses during autumn, winter and spring seasons, suggesting a cloud top ascent (implying unstable weather conditions) which is in agreement with Golden (1974a), that waterspouts usually form under convective clouds.

Acknowledgements. The authors would like to acknowledge the EUMETSAT for the data that were used in order to complete this study. Also this study was completed as part of the postgraduate program "Environmental Physics" co-funded by the Action "State Scholarships Foundation (SSF/IK $\Upsilon$ ) program with an individualized evaluation process of the academic year 2011-2012" from resources of the operational program "Education and Lifelong Learning" of the "European Social Fund (ESF) and of the National Strategic Reference Framework (NSRF), 2007-2013."

Edited by: F. Stel

Reviewed by: N. K. Kamperakis and one anonymous referee

\section{References}

Barbosa, H. A., da Silva Jr., I. W., Ertük, A. G., and Prieto, J.: The cloud-top SEVIRI data for monitoring convective storms, in: Simpósio Brasileiro de Sensoriamento Remoto, 15 (SBSR), Vol. 2, 2179-2186, 2011.

Barbosa, H. and Ertürk, A.: Using multispectral SEVIRI radiances at the top of deep convective storm as a powerful tool for short prediction in Brazil, in: 5th European Conference on Severe Storms, Stadtsala Bernlochner - Landsat - Germany, 2-3., 2009.

Bedka, K. M.: Overshooting cloud top detections using MSG SEVIRI Infrared brightness temperatures and their relationship to severe weather over Europe, Atmos. Res., 99, 175-189, 2011.

Gayà, M.: Tornadoes and severe storms in Spain, Atmos. Res., 100, 334-343, 2001.

Giaiotti, D. B., Giovannoni, M., Pucillo, A., and Stel, F.: The climatology of tornadoes and waterspouts in Italy, Atmos. Res., 83, 534-541, 2007.

Golden, J. H.: Waterspouts at lower matecumbe key, Florida, 2 September 1967, Weather, 23, 103-114, 1968.

Golden, J. H.: Waterspouts and tornadoes over south Florida, Mon. Weather Rev., 99, 146-154, 1971

Golden, J. H.: Some statistical aspects of waterspout formation, Weatherwise, 26, 108-117, 1973.

Golden, J. H.: The life cycle of Florida Keys' waterspouts I, J. Appl. Meteorol., 13, 676-692, 1974a.

Golden, J. H.: Scale-interaction implications for the waterspout life cycle II, J. Appl. Meteorol., 13, 693-709, 1974b.

Golden, J. H.: An assessment of waterspout frequencies along the U.S. east and Gulf states, J. Appl. Meteor., 16, 231-236, 1977. 
Golden, J. H.: Waterspouts, in: Encyclopedia of Atmospheric Sciences, edited by: Holton, J. R., Academic Press, Oxford, 2003, 2510-2525, doi:10.1016/B0-12-227090-8/00451-6, 2003.

Golden, J. H. and Bluestein, H. B.: The NOAA-National Geographic Society waterspout expedition, Bull. Am. Meteorol. Soc., 75, 2281-2288, 1993.

Golden, J. H. and Sabones, M. E.: Tornadic waterspout formation near interesting boundaries, Preprints, 25th Int. Conf. on Radar Meteor., Paris, Am. Meteorol. Soc., 420-423, 1991.

Groenemeijer, P. and Kühne, T.: A Climatology of tornadoes in Europe: Results from the European severe weather database, Mon. Weather Rev., 142, 4775-4790, 2014.

Hess, G. D. and Spillane, K. T.: Waterspouts in the Gulf of Carpentaria, Aust. Meteor. Mag., 38, 173-180, 1990.

Keul, A. G., Sioutas, M. V., and Szilagyi, W.: Prognosis of centraleastern Mediterranean waterspouts, Atmos. Res., 93, 426-436, 2009.

Leverson, V. H., Sinclair, P. C., and Golden, J. H.: Waterspout wind, temperature and pressure structure deduced from aircraft measurements, Mon. Weather Rev., 105, 725-733, 1977.

Matsangouras, I. T. and Nastos, P. T.: The 27 July 2002 tornado event in Athens, Greece, Adv. Sci. Res., 4, 9-13, 2010.

Matsangouras I. T., Nastos, P. T., and Pytharoulis, I.: Synopticmesoscale analysis and numerical modeling of a tornado event on 12 February 2010 in northern Greece, Adv. Sci. Res., 6, 187194, 2011.

Matsangouras, I. T., Nastos, P. T., Smith, R., Blair, D., and Dahni, R.: An objective synoptic classification of tornadic days over Greece, in: 13th Annual Meeting of the European Meteorological Society (EMS) and the 11th European Conference on Applied Climatology (ECAC), Vol. 29, 9-13 September 2013, EMS2013514, Reading, UK, 2013.

Matsangouras, I. T. and Nastos, P. T.: An online reposting system for tornadoes, waterspouts and funnel clouds activity over Greece, in: 10th International Congress of the Hellenic Geographical Society, 22-24 October, Thessaloniki, Greece, available at: http//tornado.geo.uoa.gr, 2014.

Matsangouras, I. T., Nastos, P. T., Bluestein, H. B., and Sioutas, M. V.: A climatology of tornadic activity over Greece based on historical records, Int. J. Climatol., 34, 2538-2555, 2014a.
Matsangouras, I. T., Nastos, P. T., Pytharoulis, I., and Migglieta, M. M.: Atmospheric conditions analysis of waterspout events based on thermodynamic environment and sea surface temperature distribution over south Aegean Sea, in: COMECAP2014 - ebook of contributions, edited by: Kanakidou, M., Mihalopoulos, N., and Nastos, P., Proceedings 12th International Conference of Meteorology, Climatology and Physics of the Atmosphere, Chap. Greece, Crete University Press, 191-198, 2014b.

Matsangouras, I. T., Pytharoulis, I., and Nastos, P. T.: Numerical modeling and analysis of the effect of complex Greek topography on tornadogenesis, Nat. Hazards Earth Syst. Sci., 14, 1905-1919, doi:10.5194/nhess-14-1905-2014, 2014c.

Nastos, P. T. and Matsangouras, J. T.: Tornado activity in Greece within the 20th century, Adv. Geosci., 26, 49-51, 2010 , http://www.adv-geosci.net/26/49/2010/.

Nastos, P. T. and Matsangouras, I. T.: Composite Mean and Anomaly of Synoptic Conditions for Tornadic Days over North Ionian Sea (NW Greece), in: Advances in Meteorology, Climatology and Atmospheric Physics, edited by: Helmis, C. G. and Nastos, P. T., 639-645, Springer Berlin Heidelberg, 2012.

Nastos, P. T. and Matsangouras, I. T.: Analysis of synoptic conditions for tornadic days over western Greece, Nat. Hazards Earth Syst. Sci., 14, 2409-2421, doi:10.5194/nhess-14-24092014, 2014.

Papachristopoulou, K., Matsangouras, I. T., and Nastos, P. T.: Waterspout cloud top detection using MSG SEVIRI Infrared brightness temperature over south Aegean Sea, in: COMECAP2014 e-book of contributions, Vol. 3, Proceedings 12th International Conference of Meteorology, Climatology and Physics of the Atmosphere, edited by: Kanakidou, M., Mihalopoulos, N., Nastos, P., Crete University Press, 26-30, 2014.

Rennó, N. O. and Bluestein, H. B.: A simple theory for waterspouts, J. Atmos. Sci., 58, 927-932, 2001.

Simpson, J., Roff, G., Morton, B. R., Labas, K., Dietachmayer, G., McCumber, M., and Penc, R.: A Great Salt Lake waterspout, Mon. Weather Rev., 119, 2741-2770, 1991

Sioutas, M. V.: A tornado and waterspout climatology for Greece, Atmos. Res., 100, 344-356, doi:10.1016/j.atmosres.2010.08.011, 2011.

Sioutas, M. V. and Keul, A. G.: Waterspouts of the Adriatic, Ionian and Aegean Sea and their meteorological environment, Atmos. Res., 83, 542-557, doi:10.1016/j.atmosres.2005.08.009, 2007.

Wakimoto, R. M. and Lew, J. K.: Observations of a Florida Waterspout during CaPE, Weather Forecast., 8, 412-423, 1993. 